\title{
Vulnerability Assessment of Concrete Bridges using Different Methods of Visual Inspection
}

\author{
M.L. Fadda, F. Mistretta and M.V. Piras \\ Department of Civil Environmental Engineering and Architecture \\ University of Cagliari \\ Italy
}

\begin{abstract}
This paper shows the comparisons between different methods of visual inspection used in European Countries. These methodologies are applied to the deck bridge located near Cagliari, along the SS 195 road to Capoterra. From a strategic point of view, this structure plays a key role ensuring a direct connection to different structures related to industrial and local productions and to an important touristic district. This is a prestressed concrete bridge in an aggressive marine environment, which in October 2008 was hit by a flood that caused subsidence in the foundations. The aim of our inspection is to obtain a real measure of the vulnerability through different procedures and to determine which is the best method able to give objective results.
\end{abstract}

Keywords: bridge assessment, visual inspection, structural safety, vulnerability, reliability, condition rating.

\section{Introduction}

The aim of this work is to identify a reliable procedure for the evaluation of existing structures, which is based on data obtained through visual inspections.

The fib Bulletin $n^{\circ} 17$ [1] describes visual inspection as the survey methodology most cost-efficient, which quickly provides an overview of the condition of the structure and makes it possible to report back immediately. It is the cheapest inspection type and, with experienced staff, it is also sufficient reliable. It is postulated that approximately $80 \%$ of information can be provided by visual inspections for approximately $20 \%$ of the total inspection costs. So far it has not been proved cost-effective to substitute partial or total visual inspections by test or other measurement methods. Available methods are not simple and tend to be expensive if used extensively. Data processing and interpretation of the results may also be a complex matter. Accordingly such methods are typically used in special 
inspections and are targeted to obtain specific items of information that are required in the assessment procedure. However, even when it required special inspections, the visual inspection is the first and indispensable step in an assessment process. Therefore, it is urgent to find a methodology to make it as objective as possible.

The existing structures that will be considered in this work are bridge structures. This interest is due to the fact that Italy undertakes a large financial investment in the road network, of which the bridges are the most vulnerable part. In recent years infrastructures showed a decrease of efficiency due to various phenomena such as increasing in traffic loads, increasing of speed of travel, changing of relevant legislation regarding safety standards. The functionality of the infrastructures is closely dependent on a good inspection activities, and the lack of proper and timely maintenance, involves an increase of the deterioration and therefore higher repair costs. It is therefore necessary to have an assessing method characterized by precise and standardized criteria, which allows to orient and organize all the management activities of bridge networks.

The goal of each evaluation is to verify the efficiency of the existing structure so that there is an adequate safety factor for the loads actually and/or potentially applied. Thus, all information gathered during the inspection should be developed and synthesized through a unique methodology to obtain a relevant judgment, and so the efficiency condition.

\section{Measure of vulnerability}

The processing of information gathered during the visual inspection can be performed by calculating the condition rating mark. It is a suitable numerical indicator of the condition of a population of structures of similar type, which serves for ranking of e.g. bridges in the road network as the first step in the planning process of further necessary actions. Condition rating, through deterioration classes, can be a useful aid to general prioritisation, for the primary ranking of the most damaged structures, and for screening candidate structures needing repair or rehabilitation that should be commissioned for the in-depth inspection.

In order to achieve these results, and to ensure that they describe the condition of the structure with good reliability, during calculation of the condition rating it should necessarily take into account some important element such as:

- the condition of all elements that make up the structure;

- the importance that each element has within the structural complex;

- type, severity and extent of the observed damage (length, area, volume);

- localization of defects within the element in which it was detected.

Moreover, a good evaluation method should also be:

- useful to any type of structure (static scheme);

- adapt to evaluation of any structures, regardless of the material of construction.

Through a careful bibliographical study, it has been found that many countries adopt the condition rating mark as a method of management support of network bridges. 
These country are: Austria [2], Denmark [2], Germany [2], Norway [2], Slovenia [3], United Kingdom [4], United States [4], Spain [4], Sweden [4], Switzerland [4], France [5], Italy (Cias [6], Pellegrino \& Co. [7]).

It was carried out a preliminary comparison between these methods, as shown in Tabella 1. In the table each row corresponds to a method and the columns are the fundamental features to the validity of the method (Structural element: the method allows the evaluation of every element of the structure; Importance of the element: it take into account the importance of the element within the structure; Type of damage: the method considers various type of damages; Localization of damage: it takes into account the damage position within the element; then the last two columns consider the adaptability to various structural types and the adaptability to various structural materials).

The table has been compiled with the " $\mathrm{X}$ " in case the method holds the requirement, otherwise with "-".

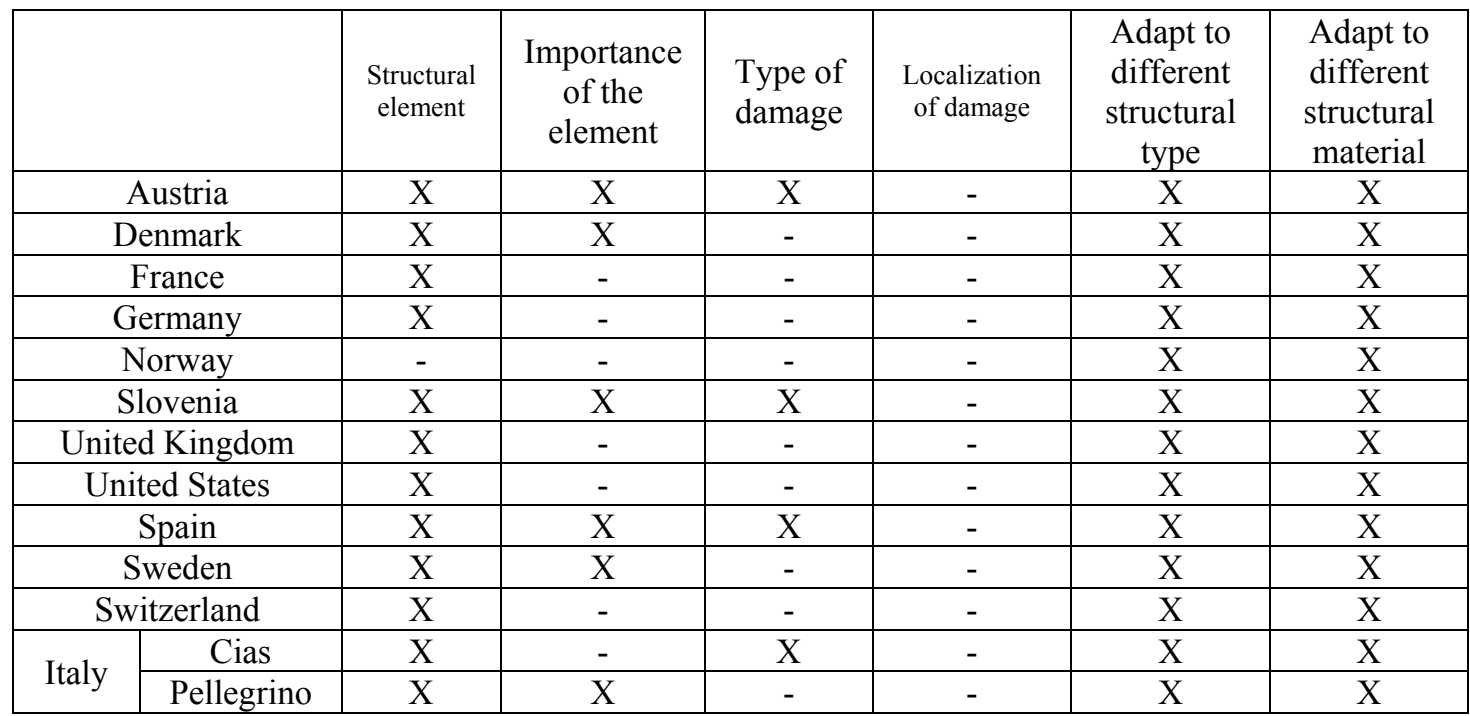

Table 1: Review of existing condition assessment

The theoretical comparison between the various methods has revealed that there are two main types of assessment approach for existing structures [8]:

- Approach 1: it is a cumulative assessment, the mark condition rating of the bridge is obtained as sum of the mark condition rating of each element (e.g. the method developed in Slovenia).

- Approach 2: recommends to assume as condition rating mark of the whole structure, the highest value among the assessed elements (e.g. the method developed in Austria). This procedure provides an approximate assessment of the degradation to the worst case condition. The results allow to determine how many bridges are there in each class of deterioration but do not allow a direct comparison between the structures.

Moreover, there is a clear difference between the methods in which the evaluation consists by assigning a unique number, representative of the degraded condition, to the structural inspected member (Denmark, France, Germany, Norway, 
United States, Sweden, Switzerland, Pellegrino) and the ones where the final condition rating mark is obtained by the calculation of the values assigned during the inspection to various type of damage (Austria, Slovenia, United Kingdom, Spain, Cias).

The first approach is definitely faster and easier than the second one, and provides sufficient data for a global level assessment (comparison between different structures), but there is a lack of assessment accuracy to make it valid at the local level (efficiency rating of the inspected bridge). The input data describes in general the condition of the inspected member, without considering the type of damage and its features (extent, severity, and localization).

Table 1 shows that Austrian, Slovenian and Spanish methods of assessment have, as compared to the other methods, a larger number of the essential requirements.

It was decided to apply the methods developed in Austria and the one developed in Slovenia to a real case, in order to test the difference between the different approaches.

\subsection{Slovenian method}

The condition rating mark of a structure is expressed by the ratio between: the effective sum of damage values obtained by taking into account from a closed list of potential damage types detected at the inspection time, and, the reference sum of damage values obtained by taking into account from the same closed list every damage type that could realistically occur on the same structure, multiplied always by unit intensity and extent factors.

The condition rating of the observed structure is defined as:

$$
R C=\left(\sum V_{D} / \sum V_{D, r e f}\right) \times 100
$$

where:

$\mathrm{RC}$ : condition rating mark;

$$
\sum V_{D}=\sum_{m=1}^{k} K_{1 m} \times M_{m}
$$

$\Sigma \mathrm{V}_{\mathrm{D}}$ : effective sum of damage value calculated for the observed structure or its part (e.g. bridge component), related to the detected types;

$\mathrm{k}$ : number of members " $\mathrm{m}$ " within the observed structure;

$\mathrm{K}_{1 \mathrm{i}}$ : factor of the structural member, which is part of the structural component, on which the damage type "i" is appearing, accounting for the member's effect on the overall safety and/or durability of the component, in the range of $0,1-0,6$;

$$
M_{m}=\sum_{i=1}^{n} B_{i} \times K_{2 i} \times K_{3 i} \times K_{4 i}
$$

$\mathrm{n}$ : number of detected and evaluated damage types "i" on a member "m";

$\mathrm{B}_{\mathrm{i}}$ : basic value associated with the damage type "i", expressing the potential effect of the damage type "i" on the safety and/or durability of the observed structural component, ranging from 1 to 4 ;

$\mathrm{K}_{2 \mathrm{i}}$ : factor indicating the intensity/degree of damage type "i", ranging from 0,5 to 2 ;

$\mathrm{K}_{3 \mathrm{i}}$ : factor covering the extent of propagation of the damage type "i" on the entire observed member or on all items of the same member type, ranging from 0,5 to 2 ; 
$\mathrm{K}_{4 \mathrm{i}}$ : factor emphasising the urgency of necessary intervention in case that the damage type "i" is directly jeopardising the safety of the component or the users, ranging from 1 to 5 .

The factors $\mathrm{B}_{\mathrm{i}}, \mathrm{K}_{1}, \mathrm{~K}_{2}, \mathrm{~K}_{3}$ and $\mathrm{K}_{4}$ are allotted through tables in which are given values and general descriptive criteria [3].

$\Sigma_{\mathrm{VD}, \text { ref: }}$ reference sum of damage values obtained by taking into account every damage type, that could potentially occur on the same observed structure or its part, multiplied by unit values of factors of intensity and extent $\left(\mathrm{K}_{2 \mathrm{i}}=\mathrm{K}_{3 \mathrm{i}}=2, \mathrm{~K}_{4 \mathrm{i}}=1\right)$;

$$
\sum V_{D, \text { ref }}=\sum_{i=m}^{k} K_{1 m} \times M_{m, r e f}
$$

As above: $\mathrm{K}_{1 \mathrm{~m}}$ ranging from 0,1 to 0,6 ; $\mathrm{k}$ number of members " $\mathrm{m}$ " within the observed structure;

$$
M_{m, r e f}=\sum_{i=1}^{t} B_{i} \times K_{2 i} \times K_{3 i} \times K_{4 i}
$$

$\mathrm{t}$ : total number of potential damage types on the member " $\mathrm{m}$ ";

As above: $B_{i}$ ranging from 1 to 4 , while the values of the other factor are: $\mathrm{K}_{2 \mathrm{i}}=\mathrm{K}_{3 \mathrm{i}}=2$ and $\mathrm{K}_{4 \mathrm{i}}=1$.

In dependence to the condition rating mark, the structure or its component, can be classified into a deterioration class, following the Table 2.

\begin{tabular}{|c|c|}
\hline Deterioration class & Condition rating values \\
\hline I & 0 to 5 \\
\hline II & 3 to 10 \\
\hline III & 7 to 15 \\
\hline IV & 12 to 25 \\
\hline V & 22 to 35 \\
\hline VI & $\geq 30$ \\
\hline
\end{tabular}

Table 2: Deterioration class (Slovenian method)

\subsection{Austrian method}

This method recommend the assessment of each element of the structure through the condition rating mark and then, the heaviest value among those obtained will be assumed as the condition rating mark of the whole structure.

The assessed condition of a bridge structure is expressed by the condition rating mark, which in general is given by the following function:

where:

$$
\text { Condition Rating mark }=\sum_{i=1}^{n} G_{i} \times K_{1 i} \times K_{2 i} \times K_{3 i} \times K_{4 i}
$$

$n$ : number of damage types " $i$ " detected and evaluated on the observed element;

$\mathrm{G}_{\mathrm{i}}$ : type of damage. The value of $\mathrm{G}_{\mathrm{i}}$ is in the range of 1 to 5 and depends on the severity of the damage. For each type of damage a description of its extent, intensity and urgency of the intervention on the particular structural member is given; 
$\mathrm{K}_{1 \mathrm{i}}$ : extent of damage. It is expressed by numerical values between 0 and 1 . It can be described by words: few or some, frequent and very frequent or large. The description usually refers to one or more components of the bridge or to the whole bridge structure. The extent is never quantified by measured sizes (length, area, etc.) of the damage;

$\mathrm{K}_{2 \mathrm{i}}$ : intensity of damage. It is expressed by numerical values between 0 and 1 . It can be also described by words: little or insignificant, medium, heavy and very heavy. The description of intensity is usually associated with the description of damage (e.g. width of cracks etc.);

$\mathrm{K}_{3 \mathrm{i}}$ : importance of the structural component or member. Values range between 0 and 1. The structural components are classified as primary, secondary and other parts;

$\mathrm{K}_{4 \mathrm{i}}$ : urgency of intervention. Values range between 0 and 10 and depend on the type, seriousness and risk of the collapse of the structure or its part.

According to the obtained value of condition rating mark, bridge structures can be ranked into one of the six classes, which are defined in Table 3 . The class 1 includes structures without deterioration (or very little), while class 6 includes structures in the worst conditions.

\begin{tabular}{|c|c|c|}
\hline Damage class & Definition & Condition Rating mark \\
\hline 1 & No or very little deterioration & $0-3$ \\
\hline 2 & Little deterioration & $2-8$ \\
\hline 3 & Medium to severe deterioration & $6-13$ \\
\hline 4 & Severe deterioration & $10-25$ \\
\hline 5 & Very severe deterioration & $20-70$ \\
\hline 6 & Very severe or total deterioration & $>50$ \\
\hline
\end{tabular}

Table 3: Class of damage (Austrian method)

\section{Case study}

In order to test the difference between the different approaches, it was decided to apply the Austria and Slovenian method, to a structure located near Cagliari, Along the SS 195 road to Capoterra.

The bridge is a deck slab supported by 14 prestressed concrete girders and 3 stringers, built in early ' $60 \mathrm{~s}$. This is placed in an aggressive marine environment, and in October 2008 it was hit by a flood that caused the subsidence in the foundations.

Figure 1 shows girders and stringers, Figure 2 the left abutment, Figure 3 the deck slab and Figure 4 shows right abutment. 


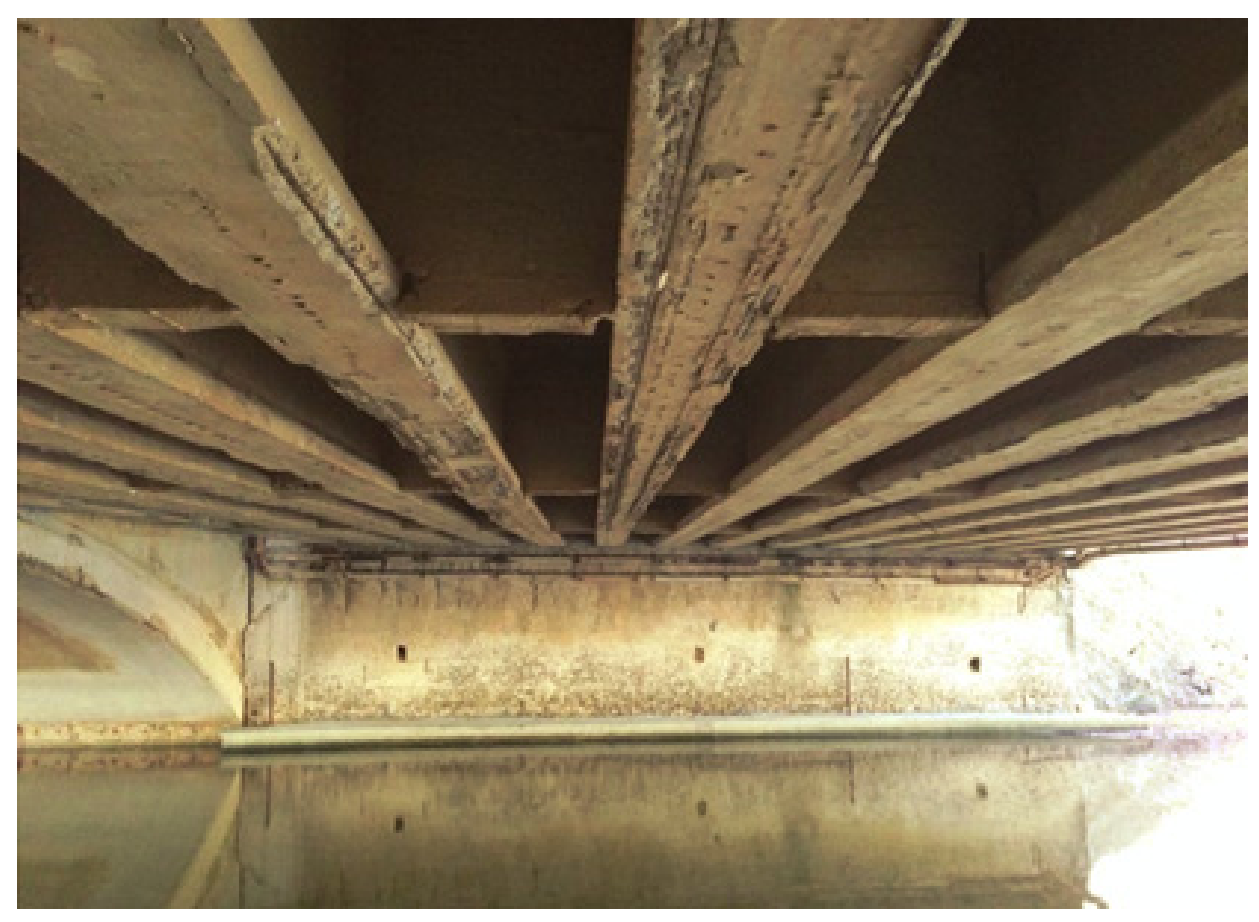

Figure 1: Girders and stringers

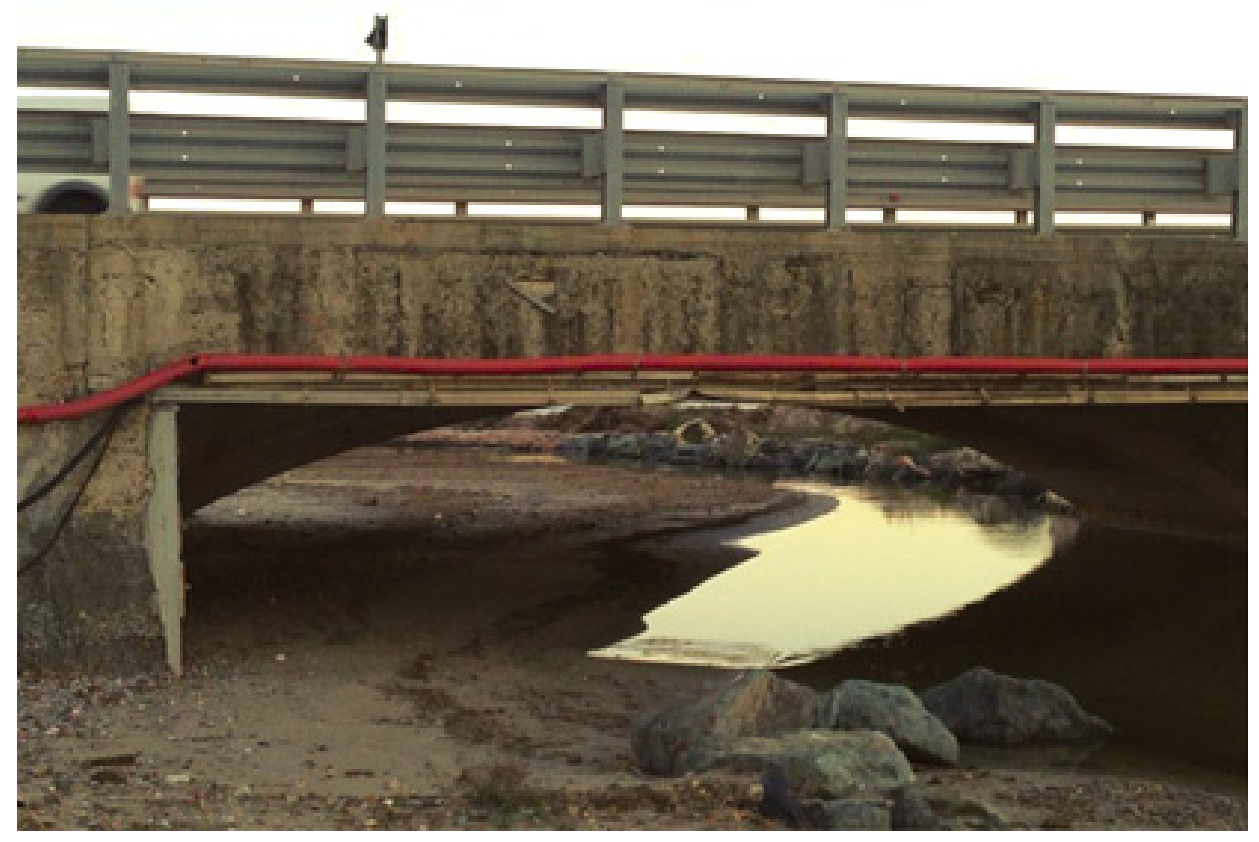

Figure 2: Left abutment 


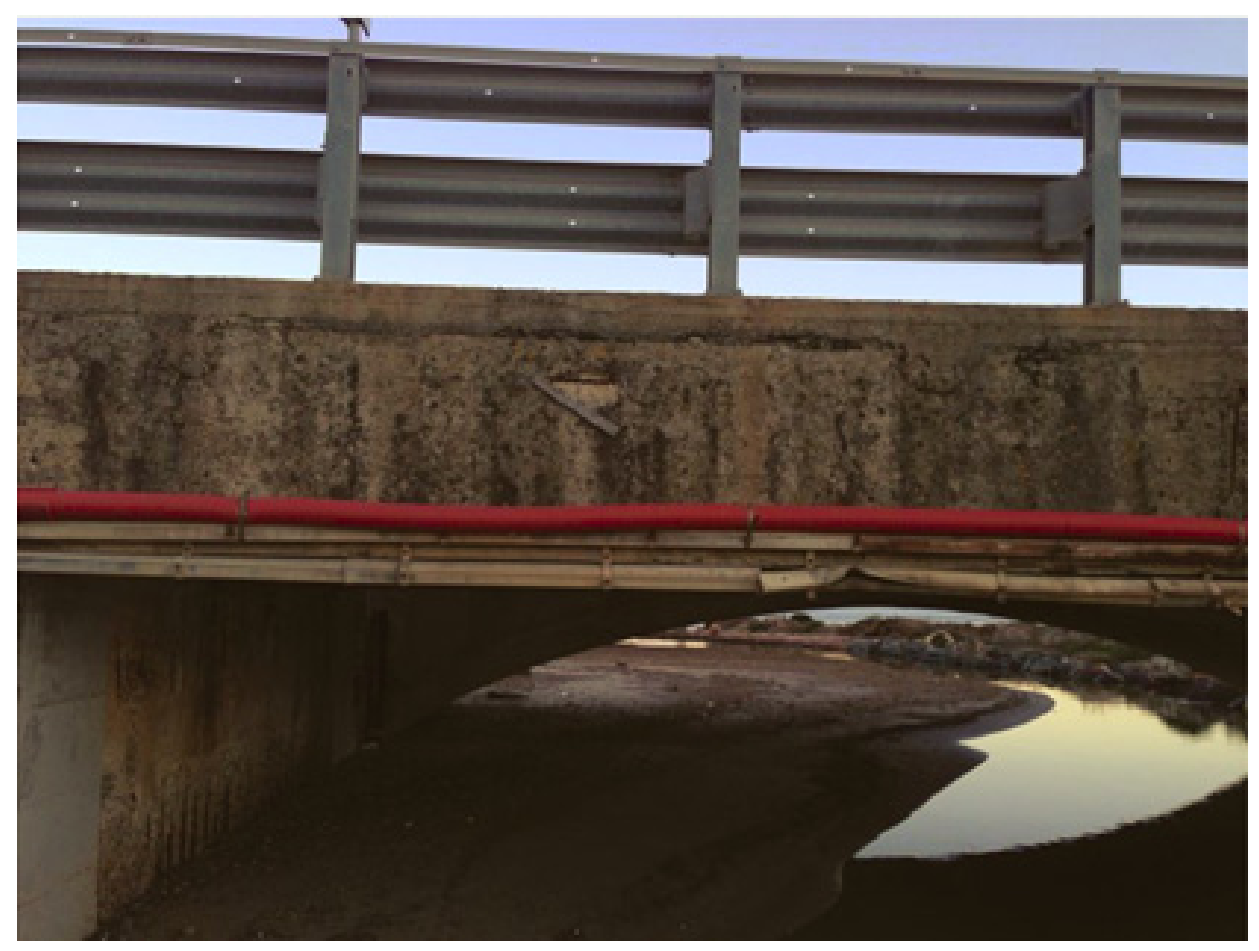

Figure 3: Deckslab

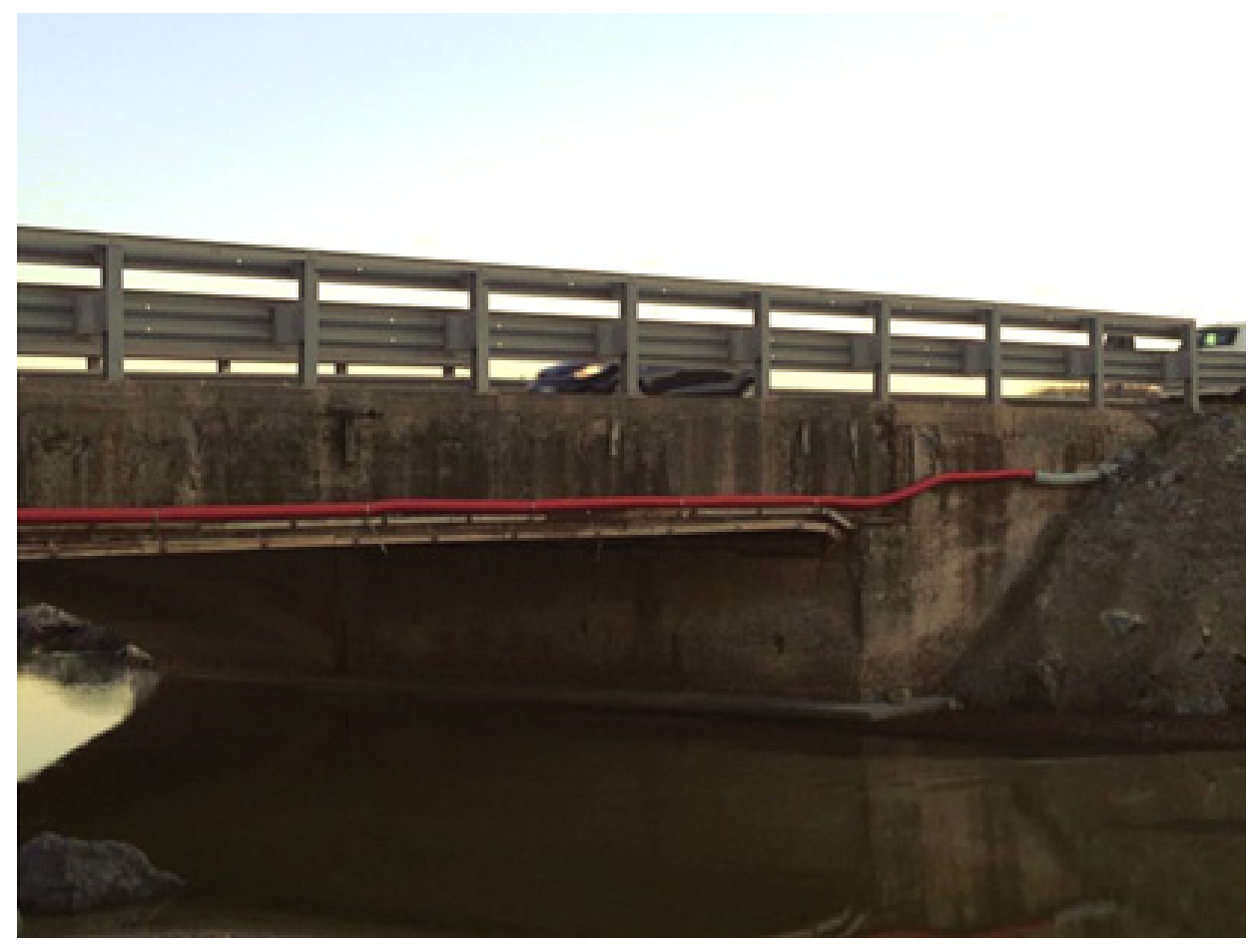

Figure 4: Right abutment 


\subsection{Application of the Slovenian method}

Table 4 shows, in detail, the application of the Slovenian method to the structural member "Girder 1".

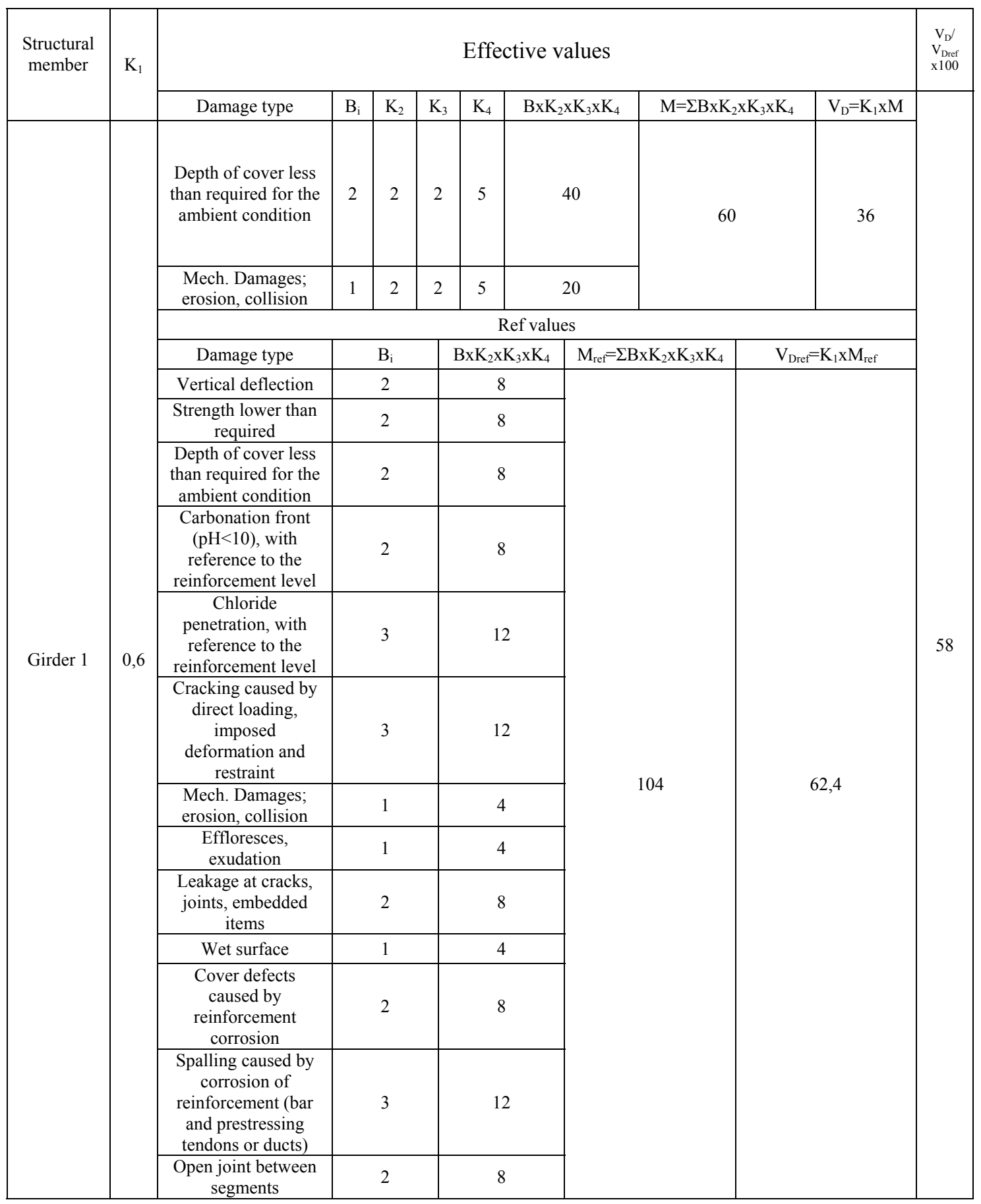

Table 4: Application of the method developed in Slovenia to the "Girder 1" 
The same procedure was applied to the other structural members. Table 5 shows briefly the results of the assessment:

\begin{tabular}{|c|c|c|c|c|}
\hline Structural member & $\mathrm{K}_{1}$ & Effective values & Ref values & $\mathrm{V}_{\mathrm{D}} / \mathrm{V}_{\text {Dref }} \mathrm{x} 100$ \\
\hline Girder 1 & 0,6 & 36 & 62,4 & 58 \\
\hline Girder 2 & 0,6 & 4,2 & 62,4 & 7 \\
\hline Girder 3 & 0,6 & 9 & 62,4 & 14 \\
\hline Girder 4 & 0,6 & 13,5 & 62,4 & 22 \\
\hline Girder 5 & 0,6 & 14,85 & 62,4 & 24 \\
\hline Girder 6 & 0,6 & 9 & 62,4 & 14 \\
\hline Girder 7 & 0,6 & 13,5 & 62,4 & 22 \\
\hline Girder 8 & 0,6 & 0,45 & 62,4 & 1 \\
\hline Girder 9 & 0,6 & 36 & 62,4 & 58 \\
\hline Girder 10 & 0,6 & 36 & 62,4 & 58 \\
\hline Girder 11 & 0,6 & 13,5 & 62,4 & 22 \\
\hline Girder 12 & 0,6 & 13,5 & 62,4 & 22 \\
\hline Girder 13 & 0,6 & 9,9 & 62,4 & 16 \\
\hline Girder 14 & 0,6 & 36 & 62,4 & 58 \\
\hline Stringer 1 & 0,6 & 36 & 57,6 & 63 \\
\hline Stringer 2 & 0,6 & 36 & 57,6 & 63 \\
\hline Stringer 3 & 0,6 & 36 & 57,6 & 63 \\
\hline Deckslab & 0,4 & 0,2 & 43,2 & 1 \\
\hline Left abutment & 0,4 & 7,2 & 52,8 & 14 \\
\hline Right abutment & 0,4 & 0,2 & 52,8 & 1 \\
\hline & & & & \\
\hline
\end{tabular}

Table 5: Application of the Slovenian method to a real case

The final value obtained for the whole structure is $\mathrm{Rc}=30$, which corresponds to a class of deterioration between the V and VI (see Table 2).

\subsection{Application of the Austrian method}

The method developed in Austria was applied, as shown in Table 5, to all the elements constituting the bridge. In this case have been taken into account two types of damage: Corrosion of reinforcement and depth of cover less than required for the ambient condition. 


\begin{tabular}{|c|c|c|c|c|}
\hline & $\begin{array}{c}\text { Damage 1 (corrosion of } \\
\text { reinforcement) }\end{array}$ & $\begin{array}{c}\text { Damage 2 (depth of } \\
\text { cover) }\end{array}$ & Rc & $\begin{array}{c}\text { Damage } \\
\text { class }\end{array}$ \\
\hline Girder 1 & 17,325 & 17,325 & 35 & 5 \\
\hline Girder 2 & 4,125 & 4,125 & 8 & 3 \\
\hline Girder 3 & 9,9 & 9,9 & 20 & 4 \\
\hline Girder 4 & 3,3 & 3,3 & 7 & 2 \\
\hline Girder 5 & 14,85 & 14,85 & 30 & 5 \\
\hline Girder 6 & 14,85 & 14,85 & 30 & 5 \\
\hline Girder 7 & 14,85 & 14,85 & 30 & 5 \\
\hline Girder 8 & 0,825 & 0,825 & 2 & 1 \\
\hline Girder 9 & 45 & 45 & 90 & 6 \\
\hline Girder 10 & 50 & 50 & 100 & 6 \\
\hline Girder 11 & 4,125 & 4,125 & 8 & 3 \\
\hline Girder 12 & 4,125 & 4,125 & 8 & 3 \\
\hline Girder 13 & 4,125 & 4,125 & 8 & 3 \\
\hline Girder 14 & 17,325 & 17,325 & 35 & 5 \\
\hline Stringer 1 & 22,5 & 22,5 & 45 & 5 \\
\hline Stringer 2 & 22,5 & 22,5 & 45 & 5 \\
\hline Stringer 3 & 22,5 & 22,5 & 45 & 5 \\
\hline Deckslab & 0,4125 & 0,4125 & 0,825 & 1 \\
\hline $\begin{array}{c}\text { Left } \\
\text { abutment }\end{array}$ & 45 & 45 & 90 & 6 \\
\hline Right & 0,825 & 0,825 & 1,65 & 1 \\
\hline abutment & & & & \\
\hline
\end{tabular}

Table 6: Application of the Austrian method to a real case

The method recommends to assume as condition rating mark of the whole structure, the highest value among the assessed elements. In this case it was found for the girder 10 and a $\mathrm{Rc}=100$, consequently, the whole structure belongs to the class of damage 6 (that means Very severe or total deterioration, see Table 3).

\section{Conclusions}

The theoretical comparison between various existing methods in the literature has revealed that there are two main types of assessment approach for existing structures: the first is a cumulative assessment, in which the mark condition rating of the bridge is obtained as sum of the mark condition rating of each element (e.g. the method developed in Slovenia), while the second method recommends to assume as condition rating mark of the whole structure, the highest value among the assessed elements (e.g. the method developed in Austria). This procedure provides an approximate assessment of the degradation to the worst case condition. The results allow to determine how many bridges are there in each class of deterioration but do not allow a direct comparison between the structures. 
Moreover, there is a clear difference between the methods in which the evaluation consists by assigning a unique number, representative of the degraded condition, to the structural inspected member (Denmark, France, Germany, Norway, United States, Sweden, Switzerland, Pellegrino) and the ones where the final condition rating mark is obtained by the calculation of the values assigned during the inspection to various type of damage (Austria, Slovenia, United Kingdom, Spain, Cias).

The first approach is definitely faster and easier than the second one, and provides sufficient data for a global level assessment (comparison between different structures), but there is a lack of assessment accuracy to make it valid at the local level (efficiency rating of the inspected bridge). The input data describes in general the condition of the inspected member, without considering the type of damage and its features (extent, severity, and localization).

It has been found that every mentioned method is useful for various structural types, independently from static scheme and building material. None of these, takes into account the location of the damage within the structural element.

However, among the different methods Austrian, Slovenian and Spanish methods of assessment have a larger number of the essential requirements.

It was decided to apply the methods developed in Austria and the one developed in Slovenia to a real case, in order to test the difference between the different approaches.

The application, to the same structure, of the two methods chosen, shows a unanimous judgment, which indicates that the structure is severely degraded and it is urgent to carry out appropriate rehabilitation works (the method developed in Slovenia, applied to the structure, gives as result a degradation class between $\mathrm{V}$ and VI, and the Austrian method the class 6).

The method developed in Austria belongs to the approach type 2, which is considered more approximate than the approach type 1. For These reasons the method developed in Slovenia is considered the most complete and valid for estimating the efficiency of a structure.

Applying the method developed in Slovenia it was found that: values of the coefficients $B_{i}$ and $K_{1}$ are established in advance and disregard what is found during the inspection, in this way they cannot be affected by inspector's subjectivity. The values of $\mathrm{K}_{2}$ and $\mathrm{K}_{3}$ are strictly tabulated on the basis of surveys performing during the inspection (measurement of defects, extent of degradation, etc.). The coefficient $\mathrm{K}_{4}$ is a parameter that emphasizes the urgency of recovery and its value is essentially dictated by the subjective judgement of the inspector.

In future studies the method described could be improved, for example, by eliminating the source of subjectivity of judgment (introduced by the K4 coefficient) and by inserting a parameter that takes into account the location of the damage within the element.

\section{References}

[1] C. Andrade \& Co, "Management, maintenance and strengthening of concrete structures”, Fib (CEB-FIP) Bulletin 17, 2002. 
[2] R. J. Woodward, "Review of current practice for assessment of structural condition and classification of defects", in BRIME PL97-2220 Deliverable D2, Project funded by the European Commission under the Transport rtd. Program of the $4 \mathrm{t}^{\mathrm{h}}$ Framework Program, March 1999.

[3] J. Appleton \& Co. "Strategies for testing and assessment of concrete structures", in CEB Bulletin d'information n²43, May 1998.

[4] K. C. Brady \& Co., "Procedures for Assessing Highway Structures", in COST345, Joint report of Working Groups 2 and 3: "Methods used in European States to inspect and assses the condition of highway structures", 2004.

[5] G. Lacoste \& Co., "Méthodes de gestion des ouverages développées par le Ministére de l'Ecologie, de l'Energie, du Dèveloppement durable et de l'Amènaement du territoire", Sétra, France, Avril 2008.

[6] M. Bruson, S. Martinello, "Valutazione della capacità portante di un ponte", Cias, 4 EMME Service S.p.A, 2005.

[7] C. Pellegrino, A. Pipinato, C. Modena, "A semplified management procedure for bridge network maintenance", Vol.7, No.5, 341-351, May 2011.

[8] J.R. Casas, "Updated inventory on condition assessment procedures for bridges Background document SB3.2”, in Suitable Bridges, Poland, 2007. 